\title{
Carbon Footprint Calculator for Paddy Production using Sustainable Web Design
}

\author{
Romiza Md Nor ${ }^{1 *}$, Nor Fatin Fazira Abu Bakar ${ }^{2}$ \\ ${ }^{1,2}$ Faculty of Computer \& Mathematical Sciences, Universiti Teknologi Mara Cawangan Perlis, Malaysia \\ Corresponding author:*romiza@perlis.uitm.edu.my \\ Received Date: 31 August 2018 \\ Accepted Date: 12 November 2018
}

\begin{abstract}
Climate change is one of the major issues that concerned by the global community. Carbon footprint calculation has evolved as one indicator to measure the concentration of the carbon emission release. Carbon footprint is the amount of carbon dioxide released into the atmosphere as the result of human activities. This research investigates the usability of the web application to increase the level of awareness towards carbon emission during paddy production. A web application called Paddy Footprint is developed by using two sustainable web design principles which are more sustainable component and user experience and design. Paddy Footprint allows users to calculate the carbon emission release resulting from the paddy production activities such as rice cultivation, fertilizer application, field burning and fuel consumption. Besides, Paddy Footprint also provides the users with information and knowledge on carbon footprint. Usability testing was conducted to evaluate the level of awareness towards environmental sustainability. The evaluation conducted involved thirty participants. From the findings, it has been discovered that through Paddy Footprint, users can calculate and display the carbon footprint for each activity. It also enhances the knowledge of participants on carbon footprint, which can encourage them to create a small step in reducing it.
\end{abstract}

Keywords: carbon footprint, carbon emission, paddy production, sustainable web design

\section{INTRODUCTION}

Climate change is one of the major issues concerned by the global community. According to Intergovernmental Panel on Climate Change (IPCC) (2013), scientific evidence for warming of the climate system was unambiguous. The Earth's climate has changed throughout the history which leads to serious natural problems such as global temperature rises; warmer atmosphere and oceans, melting of snow, rising sea level, and increased concentration of greenhouse gases (GHG). Malaysia for instance has also experienced a warming trend for a few decades. With the strong evidence of a rapid climate change, there has been an interest in studying the concentration of greenhouse gases such as $\mathrm{CO}_{2}, \mathrm{CH}_{4}$ and $\mathrm{N}_{2} \mathrm{O}$. In Malaysia, agriculture is one of the human activities, contributing 5\% to the release of GHG emission (Masud et al., 2017). In this paper, carbon footprint (CF) has been introduced to calculate the carbon emission, released in paddy production, in which paddy is one of the major agriculture sectors in Malaysia after palm oil and rubber. According to Wiedmann and Minx (2008), "the carbon footprint is a measure of exclusive total amount of carbon dioxide emissions that is directly and indirectly caused by an activity or is accumulated over the life stages of a product". Carbon footprint is important to calculate the amount of carbon emission released. Consequently, it is important to ensure the correct measurement of carbon footprints to gain a particular importance and precariousness when it comes to carbon offsetting. The carbon footprint of a product is the quantity of GHG, expressed in carbon dioxide equivalent $\left(\mathrm{CO}_{2 \mathrm{eq}}\right)$ units. 
The aim of this paper is to calculate the amount of carbon emission, released from paddy production activities such paddy cultivation, fertilizer application, field burning and fuel consumption. Finally, the carbon footprint was used to calculate and take into account all GHGs, associated with paddy production. The information will be displayed by using a web application. For paddy planting activities, 18,676 hectares are located in Perlis alone (Hussin and Mat, 2013). Thus, the potential for massive amounts of carbon emission release is higher and at stake. In order to reduce the number of carbon emission release due to paddy production activity, an effective tool to calculate the carbon emission needs to be implemented. The possible solution to overcome this problem is to develop a web application to calculate the carbon footprint for paddy production. This approach can be improved with the help of the technological appliances such as web application as it is a computer program that utilizes web browsers and web technology to perform tasks over the Internet. This project will develop a web application to motivate people in reducing the activity that potentially leads to the release of carbon by calculating the carbon footprint by using formulae.

This project incorporated green sustainable web design which is an extension of persuasive technology itself, primarily to keep people conscious towards the environment. As illustrated in Figure 1, this research explains the overall of the research where Paddy Footprint web application shows how each activity in paddy production is calculated. While sustainable web design is applied in the design of the web application where it is comprised of three elements; sustainable component, findabiity and design and user experience. The web application also has been evaluated on the usability to measure whether by using the web application could lead user to increase their awareness on environmental sustainability.

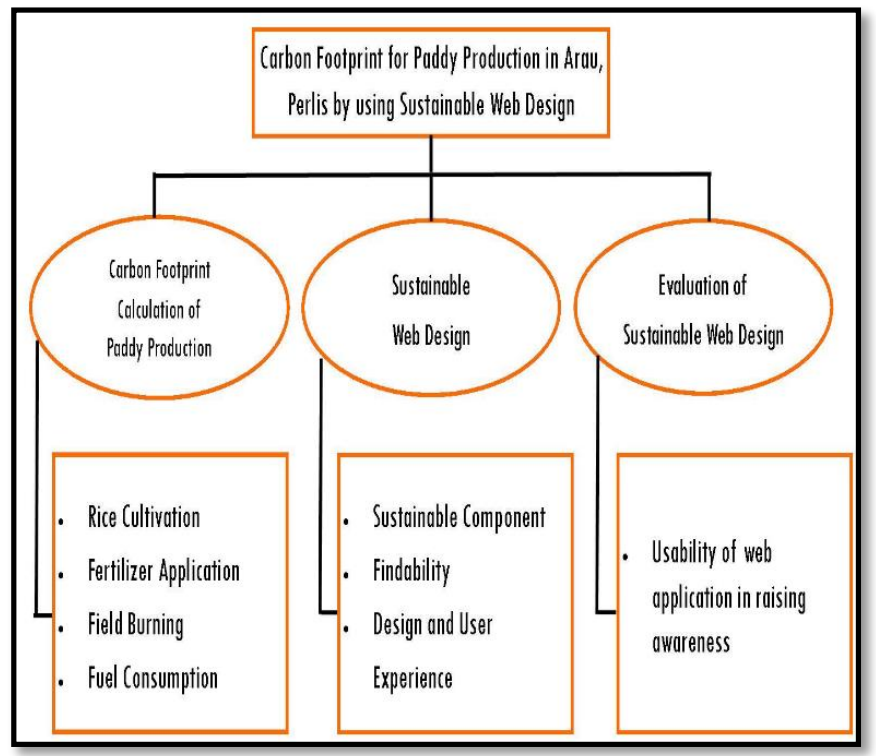

Figure 1: Research model

\section{RELATED WORKS}

\section{Carbon Footprint}

According to Pandey and Agrawal (2014), greenhouse gas (GHG) intensity for diverse products and activities has evolved as an important expression when defined in terms of carbon footprint. Scientific analyses of carbon footprint are being conducted, mainly for consumer products and industrial processes (Pandey and Agrawal, 2014). However, there is a lack of research about carbon footprint in agriculture 
sector, especially in paddy production, even though it is the fact that agriculture sector is responsible for GHG emission release to the largest degree. So, it is important to understand the term 'carbon footprint' itself so that a researcher can have a good understanding of it and conduct a study related to the topic of 'carbon footprint' in agriculture. Consequently, a carbon footprint is also important as a tool to estimate agriculture's contribution to the atmospheric stock of greenhouse gases; hence, the environmental efficiency of the agriculture sector can be improved. Moreover, carbon footprint acting as a medium and play a significant role in raising awareness and motivate people in reducing activities that can lead to the release of carbon (Nor and Hadi, 2016; Nor and Azhar, 2017).

\section{Carbon Footprint Formula for Paddy Production}

There are different carbon footprint formulae depending on what we are measuring. In this study, the calculation of carbon footprint is for paddy production involving several activities such as paddy cultivation, fertilizer application, field burning and fuel consumption. The carbon footprint formula is based on IPCC (2013). For the paddy cultivation activity, the carbon footprint formula is used to calculate the carbon emission release in cultivation area where the major source of methane $\left(\mathrm{CH}_{4}\right)$ is released in paddy fields. $\mathrm{CH}_{4}$ emissions can be affected by different factors and conditions such as soil type and temperature in the paddy cultivation area. For the second activity, the carbon footprint formula is used to calculate the carbon emission of fertilizer application activity. To increase yield, farmers commonly use fertilizers in paddy cultivation area. The application of nitrogen fertilizer in paddy fields causes the release of $\mathrm{N}_{2} \mathrm{O}$ into the atmosphere. As for the field burning activity, the carbon footprint formula is used to calculate the carbon emission of the activity. The practice of burning straw during harvesting season releases a massive amount of $\mathrm{CO}_{2}$ into the atmosphere. The amount of carbon dioxide produced during the straw burning is 13 tons per hectare. The combustion of one ton of rice straw gives a major impact to the local environment. Additionally, there are $1460 \mathrm{~kg}$ of carbon dioxide, $199 \mathrm{~kg}$ of dust, $60 \mathrm{~kg}$ of carbon monoxide, $3 \mathrm{~kg}$ of particulate material and $2 \mathrm{~kg}$ of sulfur dioxide produced and released into the atmosphere for one ton of rice straw burning. Farmers burn the straw to control rice diseases, reduce the sources of rat infestation and insect pests (Zainol et al., 2012). Lastly, the carbon footprint formula is used to calculate the carbon emission of fuel consumption activity. The greenhouse gases produced from fuel consumption is $\mathrm{CO}_{2}$ emission. The combustion of gasoline and diesel fuel from the farm tractors and harvesters release $\mathrm{CO}_{2}$ into the atmosphere.

\section{Sustainable Web Design}

Sustainable web design is a method that reduces the environmental impacts of the development of designing an energy saving and more efficient website. According to Frick (2016), sustainable web design is based on standard environmental conservation principles that can be used in the life cycle of a digital product, service, or any type of online media. These principles also reduce the carbon footprint of the web application and decrease the environmental impact. There are four primary categories that have been suggested for the sustainable web design framework but only two categories will be used in this study: more sustainable components, design and user experience. The first principle of the web application performance is where the web is lean and fast in loading the pages. The delivery of answers will be fast and it is not easily crawled websites that drive traffics. In addition, there will be improved accessibility where across the platforms and devices, the relevant content can be delivered quickly without any problem. The most important benefit of these principles is the sustainable web design principle can decrease the environmental impact. 


\section{FINDINGS}

Figure 2 shows the interface of the calculator to calculate the carbon footprint from the rice cultivation activity of paddy production. This section exposes users to the process of calculation of the carbon footprint for paddy production. To use the rice cultivation calculator, a user needs to input data for cultivation period of rice in days and the annual cultivation area harvested in hectare per year. As for the emission factor, the value has been fixed. The user only needs to select the value given in the calculator. Then, the total emission is shown in the Paddy Footprint web application report section. For a better understanding, the formulae involved in calculating the emission of the rice cultivation were displayed at the right side of the calculator.

Usability testing was conducted to evaluate the level of awareness towards environmental sustainability. The evaluation conducted involved thirty participants where the fraction in Figure 3 shows that eighteen participants strongly agree and twelve participants agree that Paddy Footprint web application encourage people to be more aware on carbon footprint. The user can make the comparison by viewing the calculation detail on the web application and visiting Paddy Footprint web application to enhance their knowledge on carbon footprint. Therefore, participants can avoid doing activities that release a large amount of carbon emission. From the findings, it has been discovered that through Paddy Footprint, users can calculate and display the carbon footprint for each activity. It also enhances the knowledge of participants on carbon footprint, which can encourage them to create a small step in reducing it.

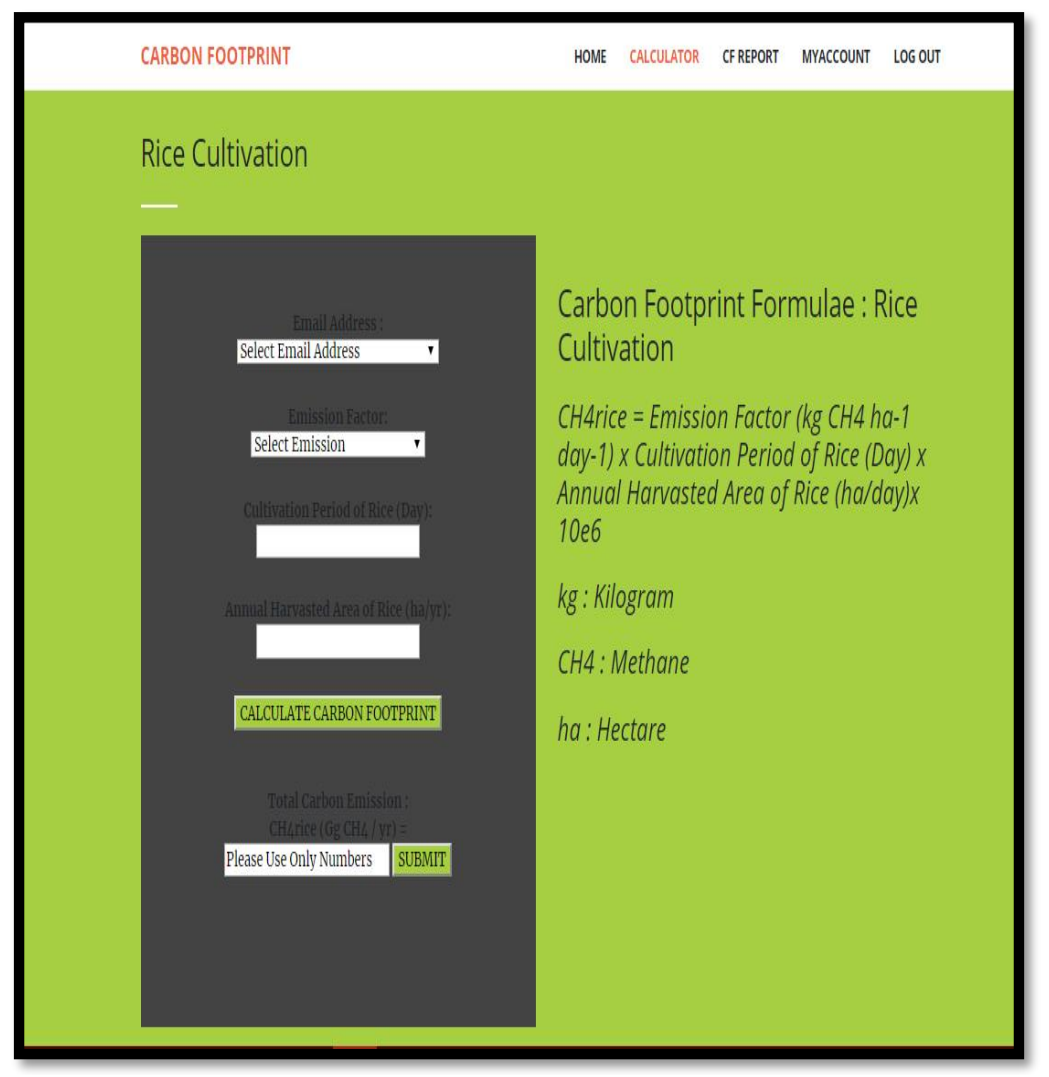

Figure 2: Rice Cultivation Carbon Footprint Calculator Interface 


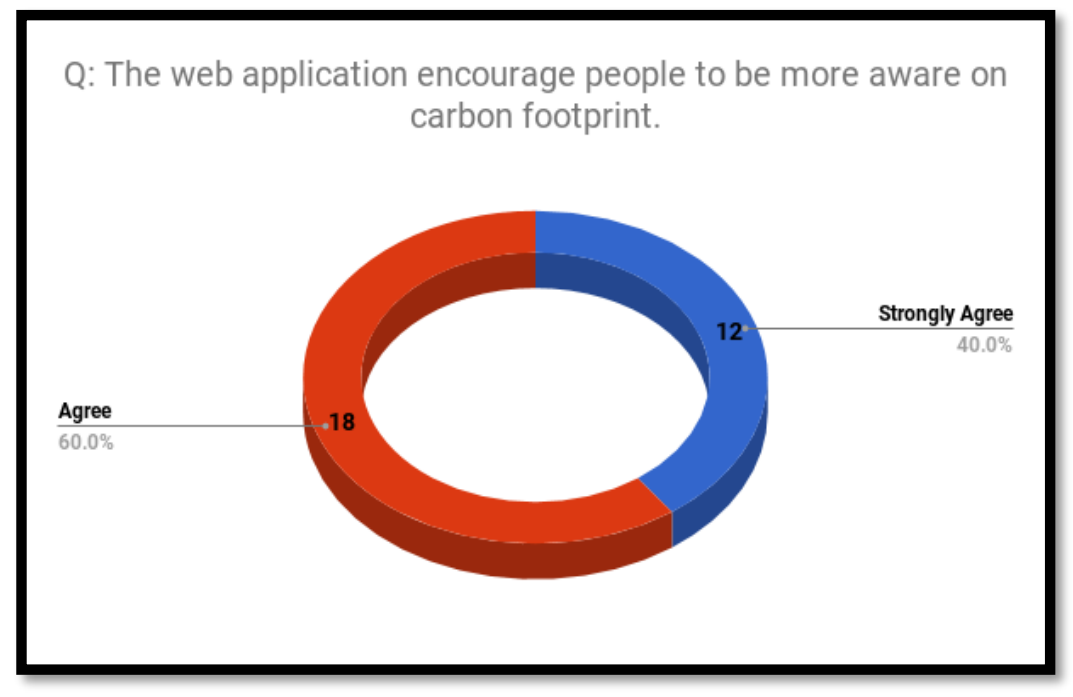

Figure3:Encourage user to be more aware of carbon footprint

\section{CONCLUSION}

Paddy Footprint is a web application that calculates the total carbon emission release from selected paddy production activities such as rice cultivation, fertilizer application, field burning and fuel consumption. The main objective of this project is to develop a web application that calculates the carbon footprint of paddy production by using sustainable web design and to evaluate the effectiveness of web application to increase awareness in environmental sustainability. By using this Paddy Footprint web application, users can enhance their knowledge and create awareness on carbon emission. The strength of this project is on the carbon footprint calculator used to calculate the total of carbon emission from the paddy production activities. The calculation of carbon footprint will encourage people to change agriculture activities in creating a small step in reducing the carbon footprint.

The result from the usability post-test evaluation proved that the Paddy Footprint web application has been successful in raising awareness in environmental sustainability through the result displayed in the web in all activities involved, tips shared in reducing carbon footprint in attractive methods such as images and videos. Design of sustainable web also were applied in this web application and that managed to reduce the environmental impacts during the development of designing energy saving and more efficient website.

\section{REFERENCES}

Frick, T. (2016). Designing for sustainability: A guide to building greener digital products and services. O'Reilly Media, Inc.

Zainol, R. M., Buang, A., Rose, R. A. C., Jabil, J. M., \& Marzuki, M. (2017). (An assessment of institutional factors in determining the sustainability of rice straw enterprises). Geografia-Malaysian Journal of Society and Space, 11(4).

Pandey, D., \& Agrawal, M. (2014). Carbon footprint estimation in the agriculture sector. In Assessment of Carbon Footprint in Different Industrial Sectors, Volume 1 (pp. 25-47). Springer, Singapore 
Hussin, F., \& Mat, A. W. (2013). Socio-economic level of paddy farmers under the management of MADA: A case study in the Pendang District, Kedah. Journal of Governance and Development, 9, 79-90.

Masud, M. M., Azam, M. N., Mohiuddin, M., Banna, H., Akhtar, R., Alam, A. F., \& Begum, H. (2017). Adaptation barriers and strategies towards climate change: Challenges in the agricultural sector. Journal of Cleaner Production, 156, 698-706.

Wiedmann, T., \& Minx, J. (2008). A definition of 'carbon footprint'. Ecological economics research trends, $1,1-11$

Eggleston, S., Buendia, L., \& Miwa, K. (2006). 2006 IPCC guidelines for national greenhouse gas inventories [recurso electrónico]: waste. Kanagawa, JP: Institute for Global Environmental Strategies.

Nor, R.M. \& Hadi, H.A. (2016). The Kids Calculator: What's Your Footprint? 2016. Malaysian Journal of Sustainable Environment, Vol 1. 2016.

Nor, R.M \& Azhar, N.A. (2017). Applying Green Gamification to Support Green Campus Initiatives in Reducing Carbon Emissions. Computing Research \& Innovation (CRINN), Vol. 2, October 2

Hartmann, D. L., Tank, A. M. K., Rusticucci, M., Alexander, L. V., Brönnimann, S., Charabi, Y. A. R., \& Soden, B. J. (2013). Observations: atmosphere and surface. In Climate Change 2013 the Physical Science Basis: Working Group I Contribution to the Fifth Assessment Report of the Intergovernmental Panel on Climate Change. Cambridge University Press. 